\title{
Workplace Incivility and Work Engagement: The Chain Mediating Effects of Perceived Insider Status, Affective Organizational Commitment and Organizational Identification
}

\author{
Ju Guo ${ }^{1}$ Y Yanjun Qiu ${ }^{2}$ Y Yongtao Gan ${ }^{3}$ \\ Published online: 23 March 2020 \\ (C) The Author(s) 2020
}

\begin{abstract}
The intention of this paper was to test the impact of workplace incivility (WPI) on work engagement of faculty members in private universities in China, exploring the correlation between them through chain mediators, which were perceived insider status (PIS), affective organizational commitment (AC), and organizational identification (OID). A quantitative analysis was used on a sample of 465 participants from 68 private universities in China. The conclusions show that WPI decreases faculty members' work engagement through the chain mediation effects of PIS, AC and OID. This study attempted to establish a three-in-series mediator model to comprehend the influence mechanism of WPI on work engagement, and the results suggest managers in private universities in China to create a working environment with no tolerance for incivility.
\end{abstract}

Keywords Workplace incivility · Perceived insider status · Affective organizational commitment · Organizational identification · Work engagement

\section{Introduction}

Workplace incivility (WPI), including rudeness, demeaning, contempt and disrespect, is high-cost for individuals and organizations. This is a common antisocial behavior in the work environment, and a large number of workers report that they have experienced such behavior (Cortina 2008). Literature review shows that incivility exists in various organizations, from medical companies to list enterprises, national sport institutions, hospitality industry, academic circle, volunteer industry and nonprofit institutions (Pearson and Porath 2005). For instance, $71 \%$ of court workers (Cortina et al. 2001), 75\% of university faculty members (Cortina and Magley 2009) and $79 \%$ of law-enforcement personals (Cortina et al. 2004) reported that in recent years they had experienced different types of uncivilized behavior in the workplace, and $85 \%$ of nurses

Yongtao Gan

1049846825@qq.com

1 School of Economics and Management, Southwest Jiaotong University, Chengdu 610031, China

2 Department of Strategy and Discipline, Southwest Jiaotong University, Chengdu 611756, China

3 Higher Education Research Institute, Shantou University, Shantou 515000, Guangdong, China had been treated uncivilly at work (Lewis and Malecha 2001). This "dark side" of organizations has shown undesirable impacts on about $98 \%$ of the workforce, half of which are treated rudely at least weekly (Andersson and Pearson 1999).

Work engagement is one of the recent job structures that draw academic's attention. It is described as a positive and job-related satisfaction mentality with vitality, dedication and absorption (Schaufeli et al. 2002). According to Kahn (Kahn 1990), staff members show participation when they play their roles physically, emotionally and cognitively at the same time. According to Gallup's specialized measurement of work engagement, Business Journal reported that $87 \%$ of workers around the world did not engage, resulting in a "global employee engagement crisis" (Mann and Harter 2016).

WPI is a comparatively recent new concept in the area of negative organizational behavior, defined as "low-intensity, disrespectful or rude deviant workplace behavior with ambiguous intent to harm the target and is in violation of workplace norms for mutual respect" (Andersson and Pearson 1999). For example, reducing the use of fundamental polite terms such as "please" and "thank you", using concise language in technical exchanges, disrespectful leaders and colleagues, or sending unkind e-mails to workmates, all these seemingly insignificant and mild actions still have adverse effects on perceived insider status (PIS), affective organizational commitment (AC), and 
organizational identification (OID), reducing work engagement. Even though unlike open hostilities such as workplace exclusion, workplace bullying, and workplace aggression (Branch et al. 2013; Herschcovis 2011; Kunkel et al. 2015), WPI not only lead to an uncomfortable working environment, but also has negative impacts on organizational performance, social reputation and organizational image. Although uncivilized behavior is not obvious and has no clear intention of hurting others (Andersson and Pearson 1999), it violates the basic norms of mutual respect and is related to passive humanrelated and work-related results when conducting research at the interpersonal level. These consequences can have devastated impacts on employee welfare and organizational attitude. Consistent with this view, Campana et al. (2013) empirical evidence has demonstrated the relationship between WPI and passive phenomena such as mental distress, job lassitude, low AC, and low job satisfaction (Laschinger et al. 2013).

Previous research into the negative impacts of WPI has concentrated on the following areas: business organization (Yan and Li 2018; Liu and Jie 2018), the nursing industry (Roberta et al. 2016; Riah and Kristy 2015), the service industry (Won-Moo et al. 2016; Zhan 2017), and the education industry (Lecturer and Ali 2016; Dorit and Yariv 2016). Although previous studies have paid attention to WPI in the education industry, few researches have conducted on the negative impacts of WPI on faculty members in private universities, or the chain mediating roles of PIS, $\mathrm{AC}$, and OID. Previous researches on work engagement have made it an independent variable (Olugbade and Karatepe 2018), or an intermediary variable (Wang and Tseng 2019; Santos et al. 2016), or a dependent variable (Els et al. 2016). However, most of the research focuses on other areas (Olugbade and Karatepe 2018; Wang and Tseng 2019; Els et al. 2016; Ancarani et al. 2017; Alessandro et al. 2018), less on private universities.

This study first examined the literature related to the correlation between WPI and work engagement, and then explored the chain mediating effects of PIS, AC and OID between the two variables. In the main part of this paper, we discussed the theoretical model and hypotheses, and elaborated the methods, and explained the source of scales and data, and displayed data analysis, and discussed the results, and expounded the theoretical and practical implications. The last part have emphasized the insufficiencies of this research and given proposals for future study.

\section{Literature review and theoretical basis}

\section{Integration of the affective event theory and the conservation of resources theory}

In this study, hypotheses are proposed with the help of the Affective Event Theory (AET) (Weiss \& Cropanzano, 1996) and the Conservation of Resources (COR) theory (Hobfoll
1989). Weiss and Cropanzano (1996) pointed out that AET elaborated on the impact of negative emotions at work employees' work attitudes and organizational performance. Moreover, Carlson et al. (2015) elaborated the impact of organizational environment on employees' emotions, and the influence of positive working attitudes on employees, indicating that the accumulation of positive emotional events will improve employees' work engagement. The influence of emotion on worker's working attitudes can be realized directly through behaviors or indirectly through viewpoints (Reich and Hershcovis 2015). For instance, if a supervisor or colleague has any signs of uncivilized behavior, workers will regard this behavior as emotional stress. It is possible to lead to harmful emotional performance, creating behavioral deviation, this supports COR theory, which assumes that workers tend to obtain, retain and conserve certain resources demanded to complete work tasks. It also describes the formation mechanism of workers' coping ability and the process of responding to job pressure. It has summarized four kinds of resources: the goal, social support, personal characteristics, and energy resources (Hobfoll 1989). Based on COR theory, when people cannot get the return of resources invested in work, they will think that there is a risk of resource loss, so they will feel the pressure from the organization or work. Beyond that, because of the background of the personnel system in China, faculty members in private universities may be more likely than employees in other industries to have the anxiety that resources investment cannot be rewarded or resources lost. As a result, they are more susceptible than any industry to stress that leads to depression (Pizam 2008), emotional disorders (Phillips et al. 2006).

Therefore, using AET and COR theory to WPI in private universities in China suggests that PIS, AC, and OID, which are positive emotional resource, service as chain mediating effects in the relation of WPI and work engagement. This is essential to the healthy development of private universities in China. This paper was built on the influence of WPI on work engagement according to AET and COR theory (Hershcovis and Barling 2010). The basic principle behind these theories is that workers' emotions are obvious when they work in unpleasant environments. They show active behaviors through positive PIS, AC, and OID. Thus, integration of AET and COR theory shows that the resources invested are recovered or not determines the employees' positive or negative attitudes towards work. Accord with AET, moods can affect employees' working attitude. Therefore, faculty members who encounter insolent behavior in private universities are more likely to feel emotional pressure, resulting in the loss of positive emotional resources accumulation and the inactive working attitude. As a consequence, they may decide to cut back their work engagement or to maintain what looks like high degree of work engagement by controlling their emotions. 


\section{Work engagement}

Since work engagement is in accordance with active organizational behavior, it has traditionally been the focus of theoretical research (Bakker and Schaufeli 2008; Bakker et al. 2011). In the organization, this concern is reasonable; some scholar think that because of the lower organizational commitment and productivity, higher negative attitudes, the staff members who do not invest in the work will create costs for the organization, so it is very important to have an active workforce (Little and Little 2006; MacLeod and Clarke 2009). Obviously, private universities should also take this into account. There are two fundamental scholastic methods of employee engagement: work engagement (Schaufeli et al. 2002) and trait-state behavioral engagement (Macey and Schneider 2008). This study focused on the former, which is extensively examined and conceptually refined, compared with the latter, and is a lively, satisfying and work-related mentality (Schaufeli et al. 2002). More specifically, it is a positive, emotional motivation, personality and universal mental state, and is a key indicator of workers' behaviors and performance-related results (Macey and Schneider 2008). Dedicated workers are those who are full of vitality and enthusiasm for their job and cannot be separated from it. They consider that work is a source of energy, want to put more energy into it, and think that challenging work is interesting, not stressful (Bakker et al. 2008). So, positive psychological character such as PIS, AC and OID may be associated with the increasing of work engagement of faculty members in private universities.

\section{Theoretical framework and research hypotheses}

\section{Relationship between workplace incivility and work engagement}

There have been few researches on the impact of work engagement on WPI, but it is a significant result related to job (Schaufeli et al. 2002) [41]. A high degree of work engagement can create effective work results and proactive $\mathrm{AC}$ (Demerouti and Bakker 2001). A recent study (Chen et al. 2013) applied self-reinforcing theory to elaborate the impact of impoliteness on work engagement, suggesting that individuals are willing to devote more effort to work in an environment that can maintain positive PIS and reduce their work input in an environment where PIS is threatened. Based on the social identification theory, when people choose a team membership to establish their social identity, they are mainly based on four psychological motivations: improving self-esteem, reducing impermanence or improving cognitive security, satisfying the sense of belonging, and finding the meaning of existence. Meanwhile, WPI can directly threaten and hinder the satisfaction of the four basic needs of individual, which has a considerable adverse effect on work engagement. Furthermore, according to the COR theory, people have the basic motivation to preserve, protect and establish the resources they value (Hobfoll and Shirom 2001). When persons are threatened by the possibility of resource loss, or the failure to obtain returns after investing resources, they will feel psychological discomfort. Therefore, it can be predicted that in the face of WPI, individuals will feel emotional pressure and tired of coping with it. This process will consume the limited internal resources of people, resulting in psychological discomfort, making them unable to concentrate on their work, reducing the degree of work engagement. Thus, this paper developed the hypothesis as follow:

Hypothesis 1 (H1): WPI negatively influences work engagement of employees.

\section{PIS, AC and OID separately mediate the relationship between workplace incivility and work engagement}

As mentioned above, many researchers have found that there is not only a direct influence, but also an indirect effect in the correlation between WPI and work engagement. For example, Guan's master dissertation chose work engagement as the result variable of WPI, and took organizational support as the moderator and $\mathrm{AC}$ as the mediating variable to discuss the impact of WPI on work engagement through empirical research (Guan 2014). In addition, researchers have found that WPI has an indirect impact on work engagement. Drawing on the stress trading model and self-determination theory, Shin and Hur (2019) proposed that workers' job insecurity and motivation acted as chain mediating roles between supervisory impoliteness and work engagement. Therefore, the indirect influence of WPI on work engagement of workers should be concerned and examined empirically. PIS, AC, and OID, which are related to each other, have been considered as chain mediators to explore the "black box" between WPI and work engagement in this paper.

The existing literatures have revealed that PIS, AC, and OID have positive impacts on work engagement. Firstly, Pan believed that PIS had a positive impact on staff engagement (Pan 2017). Li found that there were definite relationships between employees' PIS, OID, and job performance ( $\mathrm{Li}$ 2017). Zuo have explained the positive impacts of individual identity and career matching on job engagement, according to the job-personal matching theory model (Zuo 2011). Secondly, a lot of researches have suggested that AC positively affects work engagement. $\mathrm{Wu}(2012)$ believed that $\mathrm{AC}$, as an attitude variable for employees' OID could predict employees' behavior, not only reflected the degree of harmony 
between workers and organizations, but also reflected the potential performance of organizations to some extent. Liu (2016) and Liang et al. (2016) held that AC positively impacted work engagement. Thirdly, researches have shown that OID has a positive effect on workplace engagement. Richea defined OID as a self-definition of an individual due to its organizational membership, which results in the consistency of values and emotional belonging (RikeRa 2005). Li et al. (2018) found that organizational support, OID and work engagement were positively correlated, which was consistent with Cong-Cong (2014) view.

According to the theory of social identity, when people choose a group membership to establish their social identity, they are mainly based on four psychological motivations: improving self-esteem, reducing impermanence or improving cognitive security, satisfying the sense of belonging, and finding the meaning of existence (Chiu et al. 2005). The satisfaction of these four psychological motivations will directly determine the level of OID. Therefore, this study inferred that the interpersonal treatment of individuals in an organizational context should be closely related to the level of OID. Constructive ways of treatment (such as respect, mutual assistance and tolerance) can satisfy the sense of security and belonging, improve the level of AC and OID. Previous researches have shown that people' OID has an important effect on their organizational behaviors and working attitudes, those with high degrees of OID are more willing to increase their work engagement (RikeRa 2005).

Thus, as stated in the literature reviews and theories above, WPI may threaten one's PIS, AC, and OID, reduce work engagement of faculty members in private universities. Therefore, this study developed the hypotheses as follows:

Hypothesis 2 (H2): PIS mediates the negative effect of WPI on work engagement.

Hypothesis 3 (H3): AC mediates the negative effect of WPI on work engagement.

Hypothesis 4 (H4): OID mediates the negative effect of WPI on work engagement.

Hypothesis 5 (H5): PIS mediates the negative effect of WPI on AC.

Hypothesis 6 (H6): PIS mediates the negative effect of WPI on OID.

Hypothesis 7 (H7): AC mediates the negative effect of WPI on OID.

\section{The chain mediating effects of perceived insider status, affective organizational commitment and organizational identification}

The concept of PIS was first proposed by Stamper and Masterson, it referred to the level to which workers think that the organization treats them differently, that is, the organization or superior divides them into insiders or outsiders (Stamper and Masterson 2002). Chen et al. (2007) thought that PIS was workers' perception of interpersonal relationship between themselves and other members of the organization. In the light of social cognitive theory, when employees consider that the organization cherishes them, they will attribute themselves to insiders rather than outsiders. On the contrary, when they perceive incivility from a superior or colleague, they may reevaluate their relationship with the organization and decrease PIS. Therefore, WPI has a negative impact on PIS. Existing researches have indicated that employees with higher PIS exhibit more altruistic behavior and less productive deviant behavior, creating higher levels of job satisfaction, $\mathrm{AC}$, and task performance (Chen and Aryee 2007; Wang and Kim 2013), are also more willing to engage in their work (Armstrong-Stassen and Schlosser 2011).

However, compared with teachers in public universities, teachers in private universities have a kind of identity imprint of migrant workers and outsiders, which is deeply engraved on them like a lingering brand. For example, when talking about the universities they serve, teachers in public universities will call our schools, subconsciously thinking that the schools where they work in are "ours", and have a distinct sense of belonging. However, teachers in private universities lack of this sense of belonging, and have lower PIS and AC (Liang and Gao 2019). So, it can be inferred that PIS will affect individual's AC, and affect work engagement in turn.

Previous studies have indicated that positive emotions are associated with work engagement (Bakker and Demerouti 2008) and function as mediating constructs between resources and work engagement (Bakker and Demerouti 2008). Considering these findings, it can be expected that the increase of positive emotions such as PIS, AC and OID can improve work engagement. Allen and Meyer (1990) believed that organizational commitment was a mental condition, which had three dimensionalities: affective, continuance and normative commitment. Most studies adopt the widely used dimension of AC, which is also utilized in this study. AC means that people feel strongly emotionally connected with an organization, and then identify with it, participating in it and enjoying being part of it. Workers with $\mathrm{AC}$ are perceived as having a sense of belonging, which increases their OID, enhances their willingness to participate in organizational activities and achieve organizational goals, and increases their work engagement (Meyer and Allen 1991). Therefore, this study developed the hypothesis as follow:

Hypothesis 8 (H8): PIS, AC and OID act as chain mediating effects in the relationship between WPI and work engagement.

In the light of the literature reviews and theoretical expositions above, this study presented the theoretical model as Figure 1. 
Fig. 1 Conceptual model

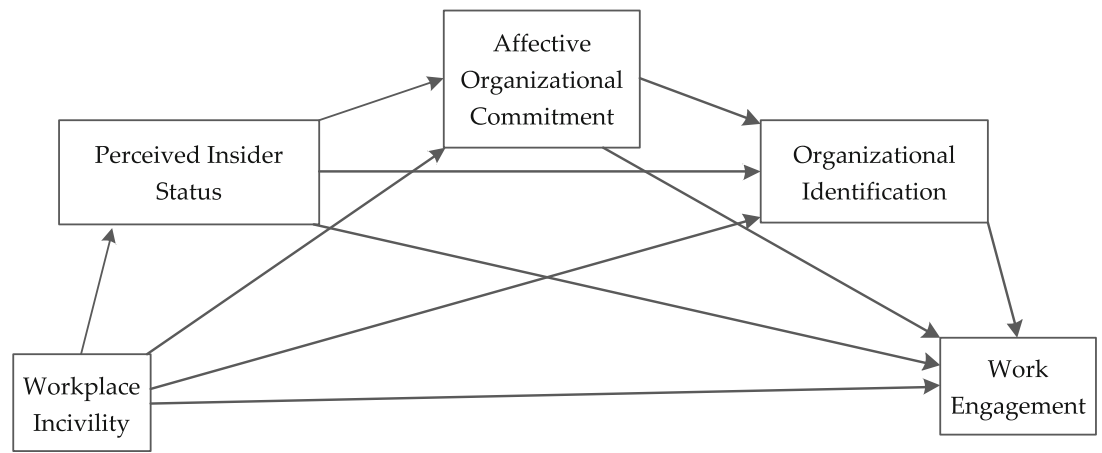

\section{Methodology}

\section{Sample and data collection}

The data of this study were collected by the Wenjuanxing, which is an online survey agency. There were some limitations to guarantee the validity of scales. For example, participants must be faculty members working in private universities, and the same IP address can only fill in the questionnaire once, to avoid repeating questionnaires. Responders came from numerous provinces across China: Yunnan, Sichuan, Jilin, Guangdong, Guangxi, Hunan, Zhejiang, Hainan, and Henan (descending rank order based on the number of respondents in each province). We sent out 505 questionnaires and recovered 465 valid questionnaires, with a recovery rate of $92 \%$. Overall, 358 participants worked in private higher vocational schools, and 107 participants worked in private undergraduate schools; 246 participants were married, and 219 participants were unmarried; 166 participants were male (35.8\%), and 299 participants were female (64.2\%). More than half of responders were between the ages of 26 and 35, accounting for $52.61 \%$; over half of them had a bachelor's degree, accounting for $54.93 \%$, and a small minority had a doctorate, accounting for $11.99 \%$. Although almost half of the respondents did not have positional job titles $(45.8 \%)$, some were professors $(9.9 \%)$. Although almost half of them had worked only for $1-5$ years $(46.8 \%)$, some had worked over 10 years (16.4\%). A total of 286 participants were teachers, 78 participants were part-time administrative teachers, and 101 participants were clerical staff members, accounting for $61.5 \%, 16.8 \%$, and $21.7 \%$, respectively.

\section{Independent variables}

Workplace incivility. A set of 12 items was compiled by Cortina et al. (2013) and used to survey the frequency of participants' personal experience of WPI. Participants responded on a Likert 5 -point scale $(1=$ few times. $5=$ many times) about the frequency of each type of uncivil treatment incident with colleagues or supervisors in the previous year. The items to which the participants responded contained the following: "noted your statements marginally or was not interested in your point of view," and "doubted your judgment on something you were responsible for." The Cronbach's alpha value of this measurement was 0.96 .

Affective organizational commitment. A set of 5 items was developed by Gao-Urhahn et al. (2016) and used to survey participants' AC. They responded to a Likert 5-point scale ( $1=$ strongly disapprove, $5=$ strongly approve). The items to which the participants responded contained the following: "I think this school where I work is worth joining," "I think this school is good to work at." The Cronbach's alpha value of this measurement was 0.88 .

Organizational identification. A set of 6 items was developed by Mael and Ashforth (1992) and adapted to measure participants' OID. They responded to a Likert 5-point scale ( 1 = strongly disapprove, $5=$ strongly approve). The items to which the participants responded contained the following: "when people express their views on my school, I am very interested," and "people praise my school; it feels like praise for me." The Cronbach's alpha value of this measurement was 0.87 .

Perceived insider status. A set of 6 items was developed by Stamper and Masterson (2002) and adapted to measure participants' PIS. They responded to a Likert 5-point scale ( $1=$ strongly disapprove, $5=$ strongly approve). The items to which the participants responded contained the following: "this school convinces me that I am a part of it," and "I feel like an internal member of this private university where I work." The Cronbach's alpha value of this measurement was 0.88 .

\section{Dependent variable}

Work engagement. A set of 9 items in Utrecht Work Engagement Scale was compiled by Schaufeli et al. (2006) and adapted to examine participants' work engagement. They responded to a Likert 5 -point scale $(1=$ never, $5=$ always). The items to which the participants responded contained the following: "I am passionate about my work," and "when I put myself into work, I feel very happy." The Cronbach's alpha value of this measurement was 0.93 . 


\section{Results}

\section{Confirmatory factor analysis}

Since data on WPI, AC, OID, and PIS were gathered from the same source. Confirmatory factor analysis was applied by applying AMOS 24.0 to assess the probability of samesource bias and examine the discriminate validity. Among 5-, 4-, 3-, and one-factor models, the 5-factor model that included all 5 variables has better data fitting (see Table 1), with $\mathrm{x}^{2} / \mathrm{df}=2.94, \mathrm{GFI}=0.86, \mathrm{AGFI}=0.82, \mathrm{TLI}=0.91, \mathrm{CFI}=0.92$, RMSEA $=0.07$. So the discriminant availability of the 5factor model is improved after comparing it with the 4-factor model, 3-factor model and the single-factor model (see Table 1).

\section{Descriptive statistics}

The descriptive statistics and correlation of all constructs were shown in Table 2, which indicated that WPI was negatively related to PIS ( $\mathrm{r}=-0.15, \mathrm{p}<0.01), \mathrm{AC}(\mathrm{r}=-0.17, \mathrm{p}<0.01)$, OID $(r=-0.15, p<0.01)$, and work engagement $(r=-0.14, p$ $<0.01)$; PIS was positively related to $\mathrm{AC}(\mathrm{r}=0.77, \mathrm{p}<0.01)$, OID $(r=0.76, p<0.01)$, and work engagement $(r=0.78, p<$ $0.01)$; AC was positively related to OID $(\mathrm{r}=0.74, \mathrm{p}<0.01)$ and work engagement $(r=0.78, p<0.01)$; and OID was positively related to work engagement $(r=0.72, p<0.01)$. Among these control variables, WPI was positively related to working seniority $(\mathrm{r}=0.12, \mathrm{p}<0.01)$; and PIS was negatively related to age $(r=-0.11, p<0.05)$, education level $(r=-0.16, p<0.01)$, positional title $(\mathrm{r}=-0.10, \mathrm{p}<0.05)$, and nature of school $(\mathrm{r}=-$ $0.15, \mathrm{p}<0.01)$ respectively; and $\mathrm{AC}$ was negatively related to education level $(\mathrm{r}=-0.14, \mathrm{p}<0.01)$, positional title $(\mathrm{r}=-0.12$, $\mathrm{p}<0.01)$, nature of school $(\mathrm{r}=-0.14, \mathrm{p}<0.01)$, and working seniority $(\mathrm{r}=-0.11, \mathrm{p}<0.05)$ respectively; and OID was positively related to gender $(r=0.10, p<0.05)$, but negatively related to education level $(r=-0.09, p<0.05)$, positional title $(r=-$ $0.14, \mathrm{p}<0.01)$, and nature of school $(\mathrm{r}=-0.09, \mathrm{p}<0.05)$

Table 1 Results of confirmatory factor analysis

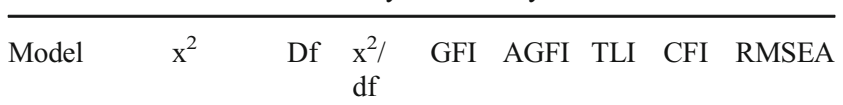

$\begin{array}{lllllllll}\text { single-factor } & 2998.16 & 665 & 4.51 & 0.26 & 0.17 & 0.41 & 0.46 & 0.19 \\ \text { Three-factor } & 2319.73 & 662 & 3.50 & 0.49 & 0.46 & 0.77 & 0.78 & 0.12 \\ \text { Four-factor } & 2251.37 & 659 & 3.41 & 0.53 & 0.45 & 0.75 & 0.76 & 0.13 \\ \text { Five-factor } & 1958.55 & 655 & 2.94 & 0.86 & 0.82 & 0.91 & 0.92 & 0.07\end{array}$

Notes: $n=465$; the sole-factor model integrates all variables into a single factor. The 3-factor model considers WPI and work engagement as 2 single factors, while integrating PIS, AC and OID into one factor. The 4-factor model considers WPI, PIS, and OID as 3 single factors, while integrating $\mathrm{AC}$ and work engagement into one factor. The 5 -factor model considers all 5 variables as independent factors respectively; and work engagement was negatively related to nature of school $(\mathrm{r}=-0.10, \mathrm{p}<0.05)$, but positively related to marital status $(\mathrm{r}=0.12, \mathrm{p}<0.01)$.

\section{Hypothesis testing}

Based on Baron and Kenny's (1986) criteria, the result of the stepwise regression analysis was shown in Table 3 , which shown that WPI negatively influenced work engagement (M11, $\beta=-$ $0.15, \mathrm{p}<0.01)$. Thus, $\mathrm{H} 1$ was verified. After the mediating variables entering, data analysis shown that 1 ) WPI negatively impacted PIS (M2, $\beta=-0.15, p<0.01)$, AC (M4, $\beta=-0.17$, p $<0.01$ ), and OID (M7, $\beta=-0.16, \mathrm{p}<0.01$ ); 2) PIS, AC, and OID had strong positive impacts on work engagement (M12, $\beta=0.77, p<0.001 ;$ M13, $\beta=0.36, p<0.001 ;$ M14, $\beta=0.24, p$ $<0.001) ; 3$ ) the negative effect of WPI on work engagement became insignificant (M12, $\beta=-0.03$, n.s.;M13, $\beta=-0.01$, n. s.; M14, $\beta=-0.01$, n. s.) with the entering of PIS, AC, and OID. Thus, H2, H3, H4 were accepted. In addition, 1) the relationships between WPI and AC, and OID became nonsignificant (M5, $\beta=-0.05$, n.s.; M8, $\beta=-0.04$, n.s.) with the entering of PIS; 2)the relationships between WPI and OID became insignificant (M9, $\beta=-0.02$, n.s.) after the addition of AC. So, H5, H6, H7 were accepted. Hence, we could conclude that WPI and work engagement have a complete mediated correlation through PIS, AC, and OID.

To examine H8, this study applied Hayes' SPSS PROCESS macro (Model 6) (Hayes 2013b), which specifies a series multiple mediators' model, and is consistent with the conceptual model of this paper. We applied three mediators (PIS, AC, and OID) in causal order, with a sample capacity of 5000 and a $95 \%$ confidence interval. We treated WPI as the independent variable (X), PIS as the first mediator $\left(\mathrm{W}_{1}\right)$, AC as the next one $\left(\mathrm{W}_{2}\right)$, OID as the last one $\left(\mathrm{W}_{3}\right)$, and work engagement as the dependent variable $(\mathrm{Y})$. Thus, the threemediation chain mediation model contains the following seven indirect effects: Ind1: $X \rightarrow W_{1} \rightarrow Y$; Ind2: $X \rightarrow W_{2} \rightarrow Y$; Ind3: $X \rightarrow W_{3} \rightarrow Y$; Ind4: $X \rightarrow W_{1} \rightarrow W_{2} \rightarrow Y$; Ind5: $X \rightarrow W_{1} \rightarrow W_{3} \rightarrow Y$; Ind6: $\mathrm{X} \rightarrow \mathrm{W}_{2} \rightarrow \mathrm{W}_{3} \rightarrow \mathrm{Y}$; Ind7: $\mathrm{X} \rightarrow \mathrm{W}_{1} \rightarrow \mathrm{W}_{2} \rightarrow \mathrm{W}_{3} \rightarrow \mathrm{Y}$.

As presented in Table 3, PIS as hypothesized, had significant positive effects on $\mathrm{AC}$, OID, and work engagement (M5, $\beta=0.76, \mathrm{p}<0.001 ; \mathrm{M} 8, \beta=0.77, \mathrm{p}<0.001 ; \mathrm{M} 12$, $\beta=0.77, p<0.001$ ), and $A C$ had positive impacts on OID and work engagement (M9, $\beta=0.37, p<0.001 ;$ M13, $\beta=$ $0.36, \mathrm{p}<0.001$ ), finally, OID had a conspicuous positive impact on work engagement (M14, $\beta=0.24, p<0.001)$. Thus, according to the joint significance test, we could judge that the chain mediation effects from WPI to work engagement were significant (Taylor et al. 2008). As shown in Table 4, the indirect impact of Ind 7 was significant with a $95 \%$ bootstrap $\mathrm{CI}$ was $[-0.04,-0.01]$ and did not contain zero $(b=-$ $0.02, \mathrm{SE}=0.01,95 \% \mathrm{CI}=[-0.04,-0.01])$. Meanwhile, the total indirect effect was also significant with a $95 \%$ bootstrap 


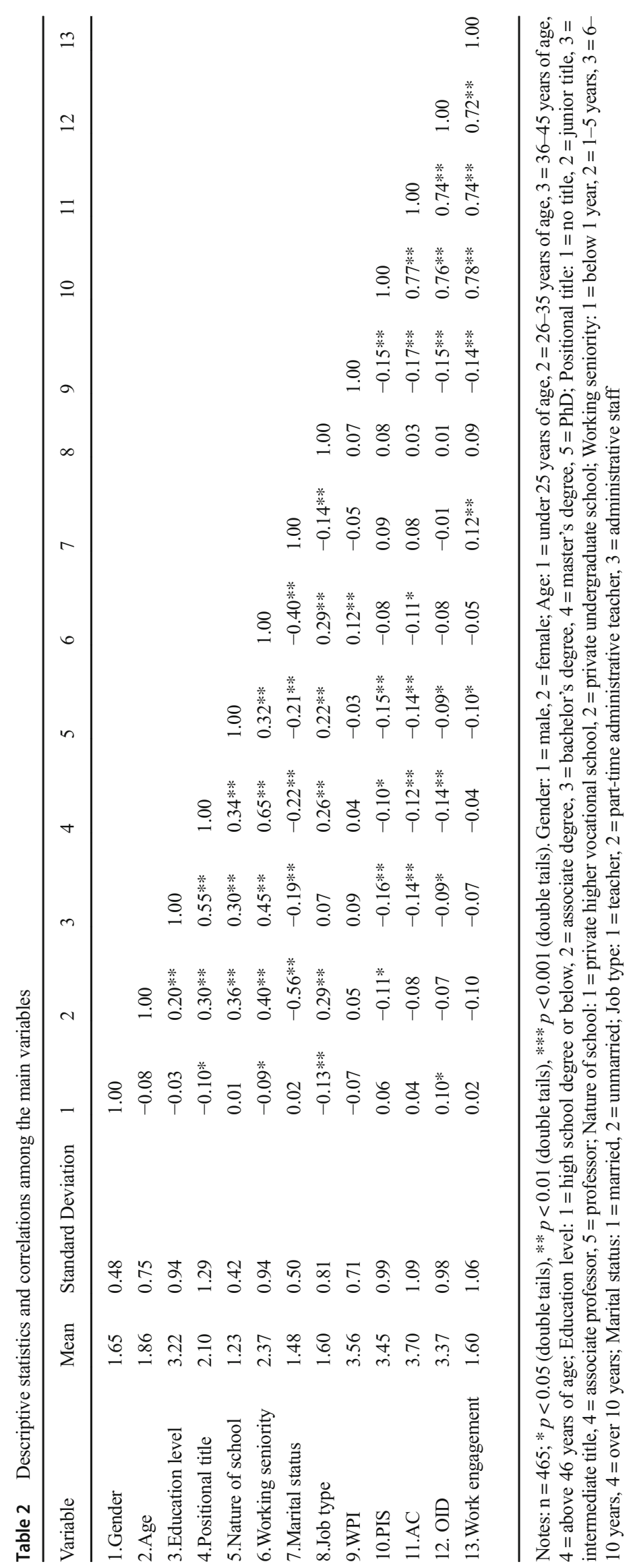




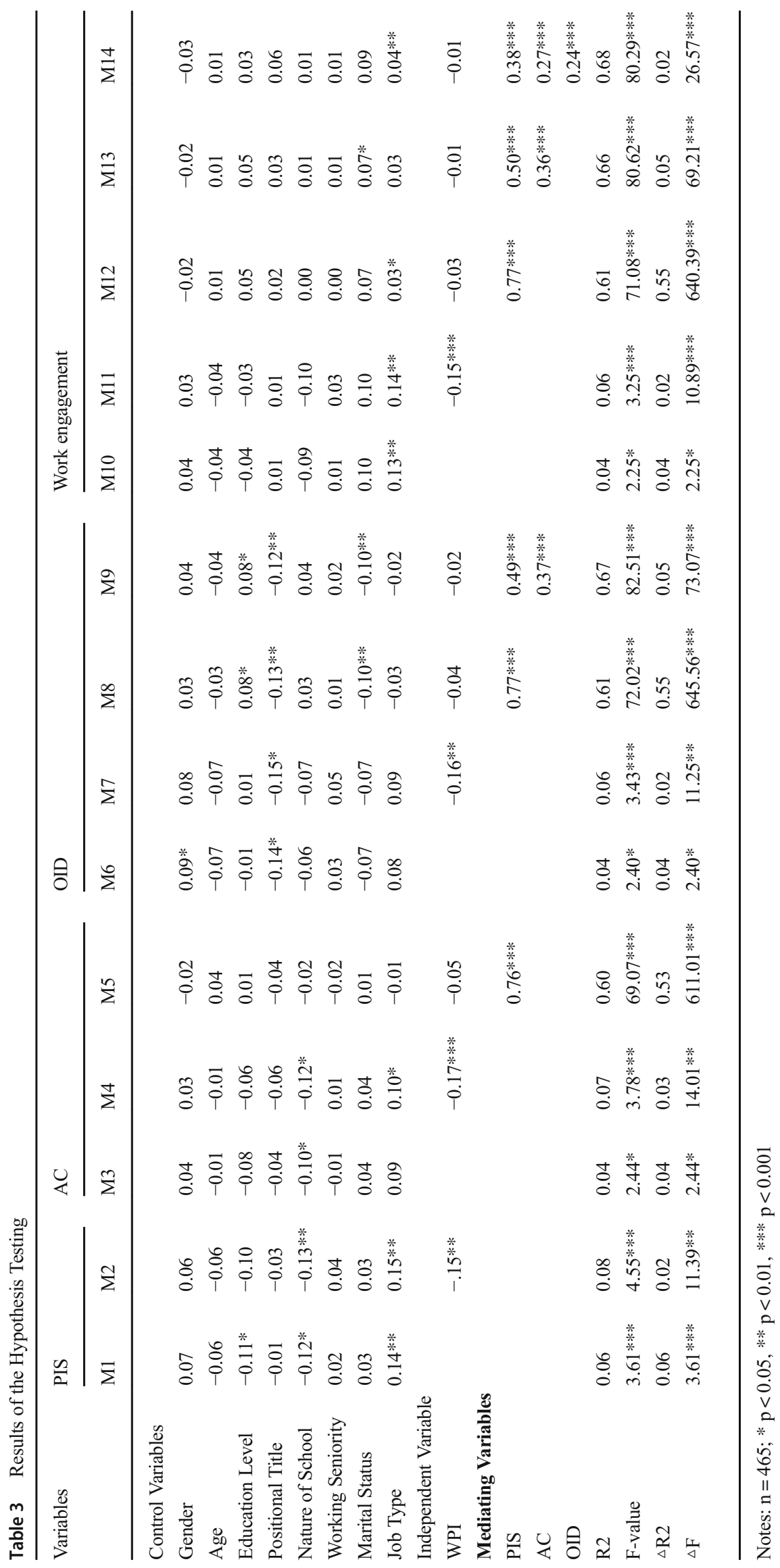


Table 4 Mediation Model: Indirect effect between workplace incivility and work engagement through perceived insider status, affective organizational commitment and organizational identification

\begin{tabular}{llll}
\hline & $b$ & Boot SE & Bootstrap 95\% CI \\
\hline Total Effect & -0.23 & 0.07 & {$[-0.36,-0.09]$} \\
Direct Effect & -0.02 & 0.04 & {$[-0.10,0.07]$} \\
Indirect Effect & -0.21 & 0.08 & {$[-0.38,-0.08]$} \\
Ind1: $X \rightarrow \mathrm{W}_{1} \rightarrow \mathrm{Y}$ & -0.09 & 0.04 & {$[-0.18,-0.02]$} \\
Ind2: $X \rightarrow \mathrm{W}_{2} \rightarrow \mathrm{Y}$ & -0.02 & 0.02 & {$[-0.06,-0.01]$} \\
Ind3: $\mathrm{X} \rightarrow \mathrm{W}_{3} \rightarrow \mathrm{Y}$ & -0.01 & 0.01 & {$[-0.03,0.02]$} \\
Ind4: $X \rightarrow \mathrm{W}_{1} \rightarrow \mathrm{W}_{2} \rightarrow \mathrm{Y}$ & -0.05 & 0.02 & {$[-0.10,-0.01]$} \\
Ind5: $\mathrm{X} \rightarrow \mathrm{W}_{1} \rightarrow \mathrm{W}_{3} \rightarrow \mathrm{Y}$ & -0.03 & 0.01 & {$[-0.06,-0.01]$} \\
Ind6: $\mathrm{X} \rightarrow \mathrm{W}_{2} \rightarrow \mathrm{W}_{3} \rightarrow \mathrm{Y}$ & -0.01 & 0.01 & {$[-0.02,-0.01]$} \\
Ind7: $\mathrm{X} \rightarrow \mathrm{W}_{1} \rightarrow \mathrm{W}_{2} \rightarrow \mathrm{W}_{3} \rightarrow \mathrm{Y}$ & -0.02 & 0.01 & {$[-0.04,-0.01]$} \\
\hline
\end{tabular}

Notes: $\mathrm{n}=465$; Model 6 (3 mediators) in the PROCESS macro. Bootstrap resample $=5000, \mathrm{~b}$ is a nonstandard regression coefficient, SE is a Std. Error, and $\mathrm{CI}$ is a confidence interval

CI was $[-0.38,-0.08]$ and did not contain zero $(b=-$ $0.21, \mathrm{SE}=0.08,95 \% \mathrm{CI}=[-0.38,-0.08])$. Results were in accordance with our hypothesis that the negative impact of WPI on work engagement was mediated by a series of mediating effects, as shown in Table 3, WPI negatively influenced PIS (M2, $\beta=-0.15, p<0.01$ ), which positively impacted $\mathrm{AC}$ in turn (M5, $\beta=0.76, \mathrm{p}<0.001$ ), which positively impacted OID in order (M9, $\beta=0.37, p<0.001$ ), which finally influences work engagement (M14, $\beta=0.24, p<0.001)$. Thus, H8 was accepted.

\section{Discussion}

\section{Evaluation of conclusions}

This paper sought to prove the effect of WPI on work engagement by checking the chain mediating roles of PIS, AC and OID. Through the combination of AET and COR theory in the construction of the theoretical framework, we found that WPI was negatively associate with PIS, AC, OID, and work engagement. The conclusion is in accordance with COR theory, that is, employees who have experienced internal identity questioning have lower $\mathrm{AC}$ and OID levels and lower work engagement. As a series of intermediary roles, PIS, AC, and OID serviced as chain mediating effects in the correlation between WPI and work engagement. Firstly, based on the theoretical model analysis, if faculty members in private universities feel incivility treatment in the workplace, they unconsciously classify themselves as outsider of the organization, lacking of a sense of ownership, and reducing the level of PIS. Therefore, $\mathrm{W}$ ) reached the same conclusion, stating that the AC of faculty members in $p$ PI had a negative effect on PIS, which accorded with Vagharseyyedin and Seyyed's (2015) view. While, PIS had a positive effect on AC, Liang and Gao (2019rivate universities will increase with the increase of OID. Similarly, AC had a positive impact on OID, echoing with the study conclusion of Wu (2012). Lastly, OID had a positive effect on work engagement, which was in accordance with Li et al.'s (2018) viewpoint. Thus, the adverse impact of WPI on work engagement was achieved through the chain mediating roles of PIS, AC, and OID.

\section{Theoretical implications}

This study tried to establish a three-serial-mediator model to explore the influence mechanism of WPI on work engagement. Although many researches on the correlations between work engagement and various variables in different contexts have been made, few studies concentrated on the impact of WPI on work engagement in private universities in China. Therefore, this study has enriched previous studies. The three cascade mediation model between WPI and work engagement are very complex, because it has seven indirect effects and one direct impact (Hayes 2013a, b). Examining the causal correlations between chain mediation variables is not only momentous for comprehending the influential mechanism of WPI on work engagement, but also is a milestone for decreasing the incivility of private universities in China.

In this study, a three-serial-mediator model was used, which supposed that there were causal chains among these mediating variables and that there were definite causal directions (Hayes 2012). The causal chain mediation path (PIS $\rightarrow$ AC $\rightarrow$ OID) was not manipulated, but proved by other studies, and was checked on the basis of AET and COR theory. For one thing, previous researches have revealed a positive correlation between PIS and AC (Liang and Gao 2019), other researchers have indicated that AC positively affects OID (Wu 2012), which positively affects work engagement (Li et al. 2018); for another AET and COR theory have clarified the chain causality between PIS, AC and OID as mentioned above. Therefore, the theoretical framework set out in the present paper is that WPI has a negative effect on PIS, which will lead to the decrease of AC and OID, and then lead to the decline of work engagement in turn.

\section{Managerial implications}

Private higher education is a momentous part of China's higher education, and its healthy development affects the interests of relevant parties. Therefore, a profound understanding of the negative impacts of WPI in private universities can help managers to take effective interventions, creating a harmonious and civilized working environment, and promoting the sustainable and healthy development of private higher education. As is known to all, work engagement serves as a key role in the development of private universities in China, 
but it is also vulnerable to the negative impact of WPI. The conclusions of this paper suggest several practice inspirations for managers in private universities. First, this study helps managers more thoroughly understand the negative impacts of WPI. Second, it illustrates the process of how WPI influences faculty members' work engagement. Since the indirect path (WPI $\rightarrow$ PIS $\rightarrow$ AC $\rightarrow$ OID $\rightarrow$ work engagement) is the strongest path, but it is also vulnerable to the negative impact of WPI, so, managers in private universities should pay more attention to faculty members' PIS, making them feel that they are part of the organization. Then managers can help employees improve their AC through some incentives and welfare benefits, thereby enhancing their OID and work engagement. Lastly, this study also recommends conducting employee-based civility intervention, because it can improve employee's resistance to any kind of impolite behavior in private universities, improving work engagement. The results in Leiter et al.'s study shown that employee-based civility intervention could ameliorate the college relations and increase employee's work engagement (Leiter et al. 2011).

\section{Research limitations and future suggestions}

This study uses regression analysis and bootstrap applying of SPSS PROCESS macro (Hayes 2013a, b) to explore the chain mediation effects, to comprehend the impact mechanism of WPI on work engagement. The contribution of this research is to enrich the previous studies in theory and provide suggestions for managers in private universities in practice. However, due to various factors, there are several deficiencies in this research and avenues for future study should be considered. First, the impact of WPI on faculty members' work engagement in private universities in China should be tested lengthwise. The single section research frame influences our clear comprehending of the causal relationship between WPI and work engagement. Future research can consider a time axis as the main line to do in-depth follow-up research, and deeply understand the deleterious impact of WPI on faculty members' work engagement in private universities, to provide strong support for the model of causality. Second, this research focused on the viewpoints of the "victim" of WPI in private universities. It may be also worthwhile to get the opinions of the instigators and witnesses of WPI. In addition, it is also meaningful to study the effects of instigated incivility and witnessed incivility on individual-level and team-level. Last but not least, a cross-perspective will be appropriate to test how the combination of various demographic factors (e.g., gender, caste, religion, regional background) can make people in Asian cultures prone to encounter or instigate WPI, and how witnesses perceive and treat such behaviors (Kabat-Farr and Cortina 2012), and it is also necessary to explore how these various social identities affect people's sense of WPI and its subsequent effects.

\section{Conclusions}

The theoretical enlightenment of this paper is to prove that the indirect effect of WPI on work engagement is achieved through PIS, AC, and OID in series. Therefore, the important implication of this study for managers in private universities is that positive mental states such as PIS, AC, and OID can improve faculty members' work engagement, but the decline of these mental states due to WPI will reduce the level of work engagement. Therefore, managers in private universities should try their best to integrate faculty members into the organization where they work in so that they can feel that they are parts of the organization, thereby improving their PIS; then, welfare measures and incentives can be taken to make faculty members have a sense of belonging to, enhancing their $\mathrm{AC}$, and then identify with the organization where they work in, improving the level of OID, and willing to improve the degree of work engagement for the healthy development of organization at last. It is hoped that this study can draw more scholars' attention to the negative effects of WPI. We suggest that future study should provide more exhaustive research on more other possible mediators such as employee satisfaction, perceived organizational support, organizational climate and work family conflict to test the causal correlation between WPI and work engagement.

Acknowledgements This study was funded by "Special Funds for Basic Scientific Research Fees of Central Universities, grant number 2682019ZT05".

Author contributions Conceptualization, J.G. and Y.G.; formal analysis, J.G.; investigation, J.G.; data curation, J.G.; writing-original draft preparation, J.G.; writing-review and editing, J.G.; supervision, Y.Q. and Y.G.

Funding information This research was funded by "Special Funds for Basic Scientific Research Fees of Central Universities, grant number 2682019ZT05".

\section{Compliance with ethical standards}

Conflict of interest The authors declare that they have no conflict of interest.

Ethical approval All procedures performed in studies involving human participants were in accordance with the ethical standards of the institutional and/or national research committee and with the 1964 Helsinki declaration and its later amendments or comparable ethical standards.

Informed consent Informed consent was obtained from all individual participants included in the study.

Open Access This article is licensed under a Creative Commons Attribution 4.0 International License, which permits use, sharing, adaptation, distribution and reproduction in any medium or format, as long as you give appropriate credit to the original author(s) and the source, provide a link to the Creative Commons licence, and indicate if changes were made. The images or other third party material in this article are included in the article's Creative Commons licence, unless indicated otherwise in a 
credit line to the material. If material is not included in the article's Creative Commons licence and your intended use is not permitted by statutory regulation or exceeds the permitted use, you will need to obtain permission directly from the copyright holder. To view a copy of this licence, visit http://creativecommons.org/licenses/by/4.0/.

\section{References}

Alessandro A., Di M C., \& Daniela G M. (2018). Linking organizational climate to work engagement: A study in the healthcare sector. International Journal of Public Administration, 1-11.

Allen, N. J., \& Meyer, J. P. (1990). The measurement and antecedents of affective, continuance and normative commitment to the organization. Journal of Occupational Psychology, 63, 1-18.

Ancarani A., Di Mauro C., Giammanco M. D. et al. (2017). Work engagement in public hospitals: A social exchange approach international. Review of Public Administration, 1-19.

Andersson, L. M., \& Pearson, C. M. (1999). Tit for tat? The spiraling effect of incivility in the workplace. Academy of Management Review, 24(3), 452-471.

Armstrong-Stassen, M., \& Schlosser, F. (2011). Perceived organizational membership and the retention of older workers. Journal of Organizational Behavior, 32(9), 319-344.

Bakker, A. B., \& Demerouti, E. (2008). Towards a model of work engagement. Career Development International, 13, 209-223.

Bakker, A. B., \& Schaufeli, W. B. (2008). Positive organizational behavior: Engaged employees in flourishing organizations. Journal of Organizational Behavior, 29, 147-154.

Bakker, A. B., Schaufeli, W. B., Leiter, M. P., \& Taris, T. W. (2008). Work engagement: An emerging concept in occupational health psychology. Work and Stress, 22, 187-200.

Bakker, A. B., Albrecht, S. L., \& Leiter, M. P. (2011). Work engagement: Further reflections on the state of play. Eur. J. Work Organ. Psychol., $20,74-88$.

Baron, R. M., \& Kenny, D. A. (1986). The moderator-mediator variable distinction in social psychological research: Conceptual, strategic, and statistical considerations. Journal of Personality and Social Psychology, 51, 1173-1182.

Branch, S., Ramsay, S., \& Barker, M. (2013). Workplace bullying, mobbing and general harassment: A review. International Journal of Management Review, 15(3), 280.

Campana, et al. (2013). Incivility from patients and their families: Can organizational justice protect nurses from burnout? Journal of Nursing Management, 23(6), 716-725.

Carlson, D. S., Kacmar, K. M., Zivnuska, S., \& Ferguson, M. (2015). Do the benefits of family-to-work transitions come at too great a cost? Journal of Occupational Health Psychology, 20, 161.

Chen, Z. X., \& Aryee, S. (2007). Delegation and employee work outcome: An examination of the cultural context of mediating processes in China. Academy of Management Journal, 50(1), 226-238.

Chen, Y., Ferris, D. L., Kwan, H. K., Yan, M., Zhou, M., \& Hong, Y. (2013). Self-love's lost labor: A self-enhancement model of workplace incivility. Academy of Management Journal, 56, 1199-1219.

Chiu, C. Y., Wen, J., \& Tan, J. B. (2005). Basic psychological processes of social identification: The case of Hong Kong's return to China. Sociology Studies, 5, 202-223.

Wang, C.-J., \& Tseng, K.-J. (2019). Effects of Selected Positive Resources on Hospitality Service Quality: The Mediating Role of Work Engagement. Sustainability, 11(8), 2320

Cong-Cong, L. (2014). The impact of organizational justice and organizational identification on nurses' work engagement. Chinese Journal of Nursing, 116(2), 473-488.
Cortina, L. M., Magley, V. J., Williams, J. H., \& Langhout, R. D. (2001). Incivility in the workplace: Incidence and impact. Journal of Occupational Health Psychology, 6(1), 64-80.

Cortina, L. M., Lonsway, K. A., \& Magley, V. J. (2004). Reconceptualizing workplace incivility through the lenses of gender and race. Paper presented at the annual meeting of the society for industrial organizational psychology, Chicago, IL.

Cortina, L. M. (2008). Unseen injustice: Incivility as modern discrimination in organizations. Academy of Management Review, 33(1), 5575 .

Cortina, L. M., \& Magley, V. J. (2009). Patterns and profiles of response to incivility in the workplace. Journal of Occupational Health Psychology, 14, 272-288.

Cortina, M., Kabat-Farr, D., Leskinen, A., Huerta, M., \& Magley, J. (2013). Selective incivility as modern discrimination in organizations: Evidence and impact. Journal of Management, 39(6), 15791605.

Demerouti, E., \& Bakker, A. B. (2001). Burnout \& engagement at work as a function of demands \& control. Scandinavian Journal of Work, Environment and Health, 27, 279-286.

Dorit, A., \& Yariv, I. (2016). Adjustment to college and perceptions of faculty incivility. Current Psychology, 35(7), 657-666.

Els, C., Viljoen, J., Beer, L. T. D., et al. (2016). The mediating effect of leader-member exchange between strengths use and work engagement. Journal of Psychology in Africa, 26(1), 22-28.

Gao-Urhahn, X., Biemann, T., \& Jaros, S. J. (2016). How affective organizational commitment to the organization changes over time: A longitudinal analysis of the reciprocal relationships between affective organizational commitment and income. Journal of Organizational Behavior, 91(4), 1106-1115.

Guan F. (2014). Research on relationship between workplace incivility and work engagement. Master Dissertation, East China University of Science and Technology, China.

Hayes, A.F. (2012). PROCESS: A Versatile Computational Tool for Observed Variable Mediation, Moderation, and Conditional Process Modeling [White Paper]. Available online: http://www. afhayes.com/public/process2012.pdf (accessed on 9 January 2019).

Hayes, A. F. (2013a). Introduction to mediation, moderation, and conditional process analysis: A regression-based approach. Journal of Educational Measurement, 51, 335-337.

Hayes, A. F. (2013b). Introduction to mediation, moderation, and conditional process analysis. New York: Guilford Press.

Hershcovis, M. S., \& Barling, J. (2010). Comparing victim attributions and outcomes for workplace aggression and sexual harassment. The Journal of Applied Psychology, 95, 874.

Herschcovis, M. S. (2011). Incivility, social undermining, bullying...oh my! A call to reconcile constructs within workplace aggression research. Journal of Organizational Behavior, 32, 499-519.

Hobfoll, S. E. (1989). Conservation of resources: A new attempt at conceptualizing stress. The American Psychologist, 44, 513.

Hobfoll S. E., \& Shirom, A. (2001). Conservation of resources theory :Applications to stress and Management in the Workplace[C]// Golembiewski R T. Handbook of Organizational Behavior. New York: Marcel Dekker, 57-80.

Kabat-Farr, D., \& Cortina, L. M. (2012). Selective incivility: Gender, race, and the discriminatory workplace. Gender and the dysfunctional workplace, $120-134$.

Kahn, W. A. (1990). Psychological conditions of personal engagement and disengagement at work. Academy of Management Journal, 33(4), 692-724.

Kunkel, D., Carnevale, J., \& Henderson, D. (2015). Examining instrument issues in workplace incivility: Measurement or mutation? Journal of Organizational Culture, Communication \& Conflict, 19(1), 102-117.

Laschinger, H. K., Wong, C., Reagan, S., Young-Ritchie, C., \& Brushell, P. (2013). Workplace incivility and new graduate nurses' mental 
health: The protective role of resiliency. The Journal of Nursing Administration, 43(7-8), 415-421.

Lecturer, R. I., \& Ali, M. (2016). Workplace incivility a hurdle in TQM practices implementation in higher education institutes of Balochistan. Journal of Education and Practice, 7, 60-72.

Leiter, M. P., Laschinger, H. K. S., \& Day, A. (2011). The impact of civility interventions on employee social behavior, distress, and attitudes. The Journal of Applied Psychology, 96(6), 1258-1274.

Lewis, P. S., \& Malecha, A. (2001). The impact of workplace incivility on the work environment, manager skill, and productivity. The Journal of Nursing Administration, 41(1), 41-49.

Liang, B., Li, S., \& He, R. (2016). The impact of rural primary and secondary school Principals' work values and organizational commitments on their work engagement. Journal of Sichuan Normal University: Social Science Edition, 6, 56-65.

Liang, S., \& Gao, S. Y. (2019). Research on Teachers' identity of private colleges and universities. Henan Education (Higher Education), (3)

Li, J., Zhu, M., \& Xu, P. (2018). A study on the relationship between perceived organizational support, organizational identification and job engagement of non-establishment staff in public hospital. Chinese Journal of Health Policy, 11(04), 68-72.

$\mathrm{Li}, \mathrm{X}$. (2017). A review of the relationship among employee internal identity, organizational identity and job performance. Operation and Management, 12, 46-50.

Little, B., \& Little, P. (2006). Employee engagement: Conceptual issues. Journal of Organizational Culture, Communications and Conflict, $10,111-120$.

Liu, C. H., \& Jie, X. W. (2018). A study of the effects of superiors' disrespectful behavior on employees' creativity based on a series mediation model. Jiangsu Social Sciences, 3, 165-174.

Liu, Z. (2016). The mediating effect of clinical nurses' professional benefit on organizational commitment and work engagement. Chinese Journal of Modern Nursing, 22(35), 5060-5064.

Macey, W. H., \& Schneider, B. (2008). The meaning of employee engagement. Industrial and Organizational Psychology, 1, 3-30.

MacLeod, D., \& Clarke, N. (2009). Engaging for success: Enhancing performance through employee engagement. A report to the UK Government

Mael, F., \& Ashforth, B. E. (1992). Alumni and their alma mater: A partial test of the reformulated model of organizational identification. Journal of Organizational Behavior, 13(2), 103-123.

Mann, A., \& Harter, J. (2016). The worldwide employee engagement crisis. Retrieved from http://www.gallup.com/businessjournal/ 188033/worldwide-employeeengagementcrisis.aspx?g_source= Business\%20Journal\&g medium $=$ CardRelatedItems \& g campaign=tiles.

Meyer, J. P., \& Allen, N. J. (1991). A three-component conceptualization of organizational commitment. Hum. Resour. Manage. Rev., 1, 6189.

Olugbade O. A., Karatepe O. M. (2018). Stressors, work engagement and their effects on hotel employee outcomes. The Service Industries Journal, 1-20.

Pan, P. (2017). A study on the impact of insider identity perception on new Employees' work engagement. Master Dissertation, Nanjing University of Aeronautics and Astronautics, China.

Pearson, C. M., \& Porath, C. L. (2005). On the nature, consequences and remedies of workplace incivility: No time for nice? Think again. Academy of Management Executive, 19(1), 7-18.

Phillips, B., Tsu Wee Tan, T., \& Julian, C. (2006). The theoretical underpinnings of emotional dissonance: A framework and analysis of propositions. Journal of Services Marketing, 20, 471-478.
Pizam, A. (2008). Depression among foodservice employees. International Journal of Hospitality Management, 27, 135-136.

Reich, T. C., \& Hershcovis, M. S. (2015). Observing workplace incivility. The Journal of Applied Psychology, 100, 203.

Riah, L., \& Kristy, C. (2015). Workplace incivility: Promoting zero tolerance in nursing. Journal of Radiology Nursing, 34(4), 222-227.

RikeRa, M. (2005). Organizational identification: a meta-analysis. Journal of Vocational Behavior, 66, 358-384.

Roberta, F., Heather, K., Spence, L. M., \& Leiter, P. (2016). The protective role of self-efficacy against workplace incivility and burnout in nursing: A time-lagged study. Health Care Management Review, 10, $156-167$.

Santos, A., Chambel, José, M., \& Castanheira, F. (2016). Relational job characteristics and nurses' affective organizational commitment: The mediating role of work engagement. Journal of Advanced Nursing, 72(2), 294-305.

Schaufeli, W. B., Salanova, M., Gonzalez-Roma, V., \& Bakker, A. B. (2002). The measurement of engagement and burnout: A two sample confirmatory factor analytic approach. Journal of Happiness Studies, 3(1), 71-92.

Schaufeli, W. B., Bakker, A. B., \& Salanova, M. (2006). The measurement of work engagement with a short questionnaire a crossnational study. Educational and Psychological Measurement, 66(4), 701-716.

Stamper, C. L., \& Masterson, S. S. (2002). Insider or outsider? How employee perceptions of insider status affect their work behavior. Journal of Organizational Behavior, 23(8), 875-894.

Taylor, A. B., Mackinnon, D. P., \& Tein, J. Y. (2008). Tests of the threepath mediated effect. Organizational Research Methods, 11(2), 241-269.

Vagharseyyedin, A., \& Seyyed, C. (2015). Workplace incivility: A concept analysis. Contemporary Nurse, 50(1), 115-125.

Wang, J., \& Kim, T. (2013). Proactive socialization behavior in China: The mediating role of perceived insider status and the moderating role of supervisor's traditiona1ity. Journal of Organizational Behavior, 34(3), 389-406.

Weiss, H.M., \& Cropanzano, R. (1996). Affective events theory: A theoretical discussion of the structure, causes, and consequences of affective experiences at work. In research in organizational behavior:An annual series of analytical essays and critical reviews; Elsevier: Amsterdam, the Netherlands, 18.

Won-Moo, et al. (2016). The effect of workplace incivility on service employee creativity: The mediating role of emotional exhaustion and intrinsic motivation. Journal of Services Marketing, 30(3), 302-315.

$\mathrm{Wu}, \mathrm{Y}$. (2012). The relationship between organizational commitment and work engagement of knowledge workers. Doctoral dissertation, Nanjing University of Science and Technology, China.

Yan, Y., \& Li, T. (2018). An analysis of the reverse mechanism how the victim turn into an instigator on workplace incivility. Advances in Psychological Science, 26, 1307-1318.

Shin, Y., \& Hur, W.-M. (2019). Supervisor incivility and employee job performance: The mediating roles of job insecurity and Amotivation. The Journal of Psychology, 16(4), 5634.

Zhan, X. (2017). The impact of workplace uncivilized behaviors on service sabotage. Contemporary Finance \& Economics, 7, 81-91.

Zuo, Y. (2011). Individual identity and job matching affect job engagement. Social Psychological Science, 1, 111-114.

Publisher's Note Springer Nature remains neutral with regard to jurisdictional claims in published maps and institutional affiliations. 